\title{
Brain Cortex Response as an Indicator of Selection and Continuity of Gifted Weightlifters
}

\section{Dr. Ahmed Awad Hassan}

\section{Introduction}

The success of the sports training process depends on many factors where good planning of training programs and the provision of resources and capabilities are necessary for training, but it all depends on the coach's success in selecting the best elements that are a good investment for all of the above. (Awed, A. 2019)

Selecting athletes is the process of choosing the best elements among athletes who have special preparations and capabilities that are in line with the requirements of the sporting activity, choosing those who have the chance and can be expected to succeed in that activity.( Khaled, E. 2013, Akyüz, M., Agar, M., Akyüz, Ö., \& Dogru, Y. 2016)

Weightlifters selection is a delicate process that aims to choose the best elements that have physical capabilities such as maximum muscle strength, explosive strength, agility, flexibility, and psychological determinants such as courage, perseverance, and physiological integrity. (Hassan, A. 2014)

The goals of selecting youngsters can be determined in the following points: early detection of talented people, directing young people to the appropriate sporting activity for their abilities, determining the ideal parameters for the selection of players for each activity, saving time, effort and money, good guidance for the training process .( Porat, Y., Lufi, D., \& Tenenbaum, G.1989. Kurade, N. P.2014)

It has been the practice to select young players based on physical and skill components without paying attention to their psychological abilities and their mental response to the activity practiced, which makes many players leave the activity practiced even after achieving high levels due to psychological problems like inconsistency with it. ( Daus, A. T., Wilson, J., \& Freeman, W. M.1986, Ebada, K. 2011, Awad, A.2017)

The brain response to the same event varies with different people, which is reflected in both physical and psychological performance. The weakness of the physical side can be overcome by the continuous development of physical capabilities and continuous training on different skills; however, the psychological response remains buried and is waiting for either the moment of change and harmony with performance and activity or turn into repulsion and leave sports activity (Grossmann, T., \& Johnson, M. H, 2010)

The Emotive Insight (fig.1) is an electronic headphone that uses 5 channels of EEG to sense brain activity and two CMS / DRLa references (left / right mastoid process alternative) during different activities, and it can be connected by phone or computer through Bluetooth. (Strmiska, M., Koudelková, Z., \& Žabčíková, M. 2018). And it can measures 6 different cognitive states Interest, Excitement, Engagement, Stress, Attention and Meditation (Relaxation). 


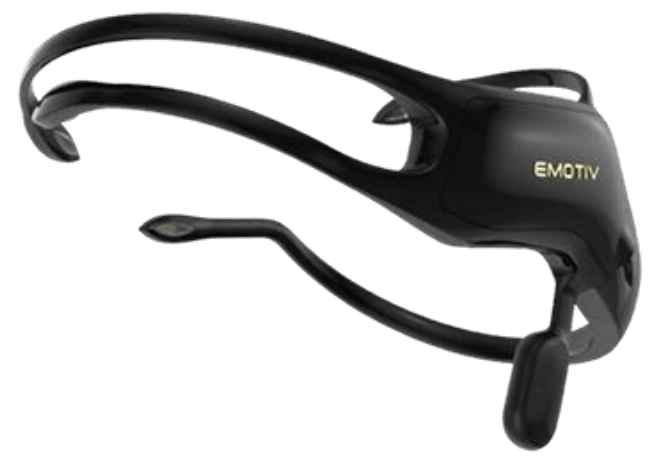

Fig.1. Emotive Insight

Interest Indicator measures the amount of what you like or dislike about something. This means the extent of your mind's interest in practicing exercises related to the sports activity practiced or not. The greater the amount of your interest during performing the exercises indicates to the correctness of the youth's selection to practice this type of sports activity. (Emotive.2019)

Excitement Indicator measures the level of mental arousal of the player during the performance of various activities, and the higher excitement indicates that the practiced activity could attract players and motivate them to perform. (Strmiska, M., Koudelková, Z., \& Žabčíková, M. 2018)

\section{Material and Methods}

The Descriptive Approach was used due to its relevance to the research idea. The sample consisted of 30 boys and girls aged $12.47 \pm 0.50$ chosen by purposive method of the beginners who were selected for the National Project for the Gifted in Damietta 10/2017.

Initially, talented players were selected and directed to the sport of weightlifting through a set of physical, skills, and standardized tests nationwide. (Attachment 1)

I was one of the members of the selection committee for talented players in Damietta Governorate, and therefore I noticed that the focus is on testing the physical and skill abilities only and the Psychological aspect in selection was not taken into consideration, which prompted me to follow the different psychological changes of the players during the performance next three months and track their record levels for two years to know the extent of the psychological factor effect in The continuity of players and their access to advanced levels

After selecting the young players, the traditional weightlifting training program has been applied for a period of 3 months, starting from 1/11/2017 to 31/01/2018, at 3 training units per week. Unit duration was 90 minutes. The training program contained basic exercises (snatch, clean and jerk, front legs, back legs, snatch pull, clean and jerk pull, and some varied strength exercises), focusing on performance more than intensity.

It was planned to track three indicators (Excitement-Interest-Engagement) resulting from the electrical signals of the brain, as evidence of the players' compatibility with the specialized exercises for weightlifting and accordingly to verify the validity of their choice to exercise the weightlifting activity.

However, after tracking these indicators for a full three-month period to identify the averages of these indicators among the players during the training units by three measurements for each player before, middle and after the training unit. It was found that fluctuations in the results of the (Engagement) indicator could not be adjusted statistically, so it was excluded at final results and the two indicators (Interest-Engagement) were adopted instead. 
Finally, we were keen to follow the attendance and absence levels of the players, in order to know that the differences in the level were not due to the lack of regularity in training. (Attachment 2)

\section{Statistical Analysis}

All statistical formulas were calculated using Excel and SPSS programs.

\section{Results}

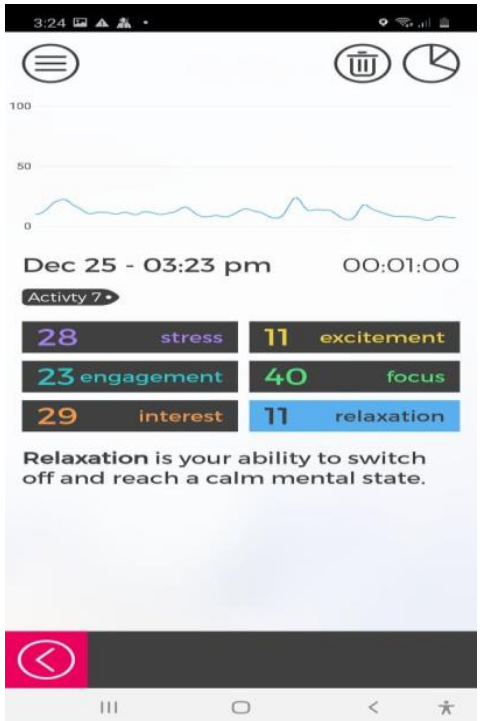

1

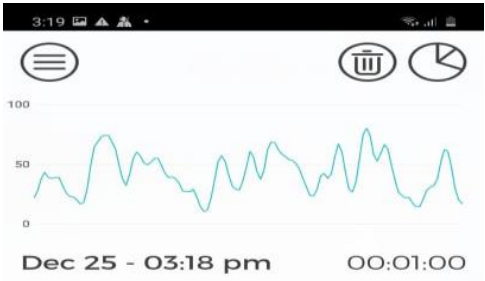

Sports7?

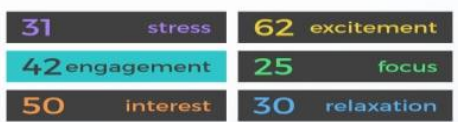

Engagement measures how mmersed you are in what you are doing or experiencing.

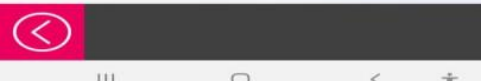

2

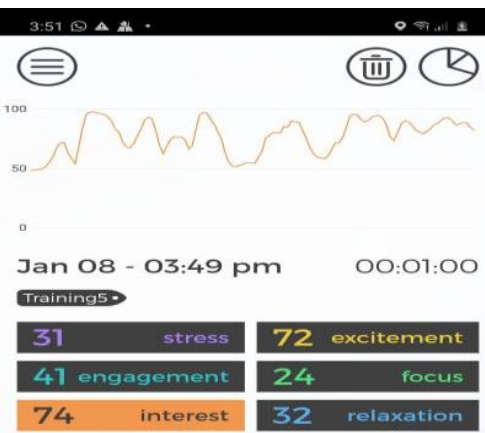

Interest measures how much you like or dislike something. Midrange

\section{(<)}

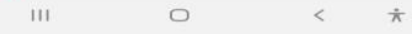

3

Fig.2. Samples Emotive Insight Indicators Results for the three groups

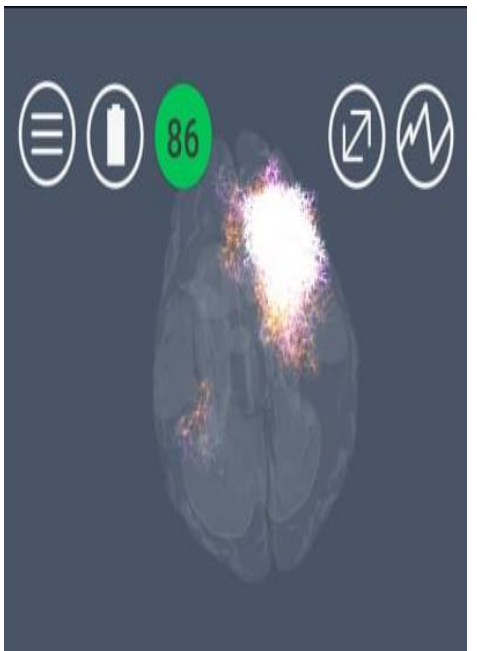

1

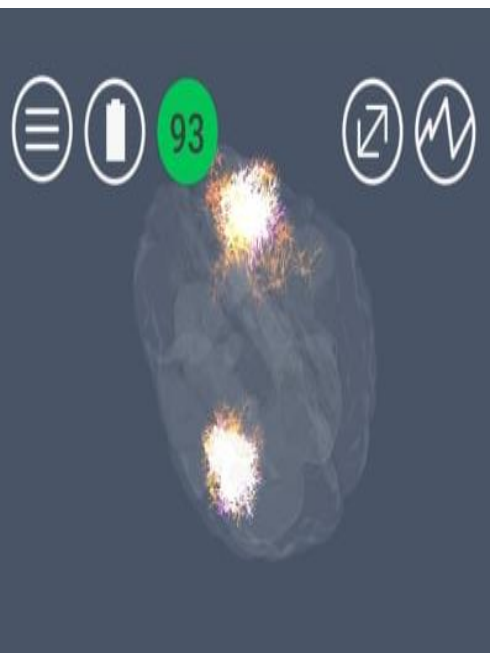

2

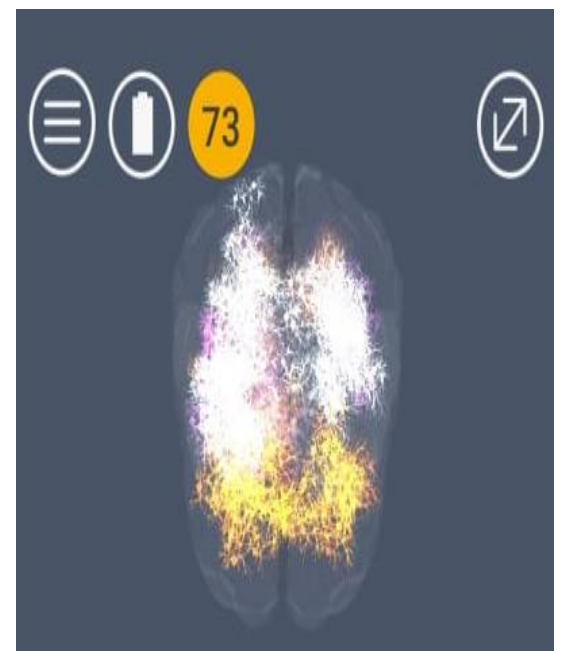

3

Fig.3. Sample patterns of brain activity for the three groups

Table (1) shows the averages of measures of interest and Excitement during the training program, which applied for three months, as well as the best group of snatch, clean and jerk at the end of each year of training. 
Table (1) average of interest and excitement, and total of two years for the three levels

\begin{tabular}{|c|c|c|c|c|c|c|c|c|c|c|}
\hline & & Age & $\mathbf{G}$ & B.C & Interest & Excitement & $\begin{array}{c}\text { First Total } \\
\text { After } 3 \\
\text { months } \\
\text { Training Pr. }\end{array}$ & $\begin{array}{c}\text { Second Total } \\
\text { Republic CH. } \\
\text { 10/2018 }\end{array}$ & $\begin{array}{l}\text { Third Total } \\
12 / 2019 \\
\text { Olympic } \\
\text { Center.maadi }\end{array}$ & NOTES \\
\hline \multirow{7}{*}{ H } & 1 & 12 & $\mathrm{~F}$ & 45 & 68 & 67 & 70 & 110 & 140 & AFRO-ASIA CO. \\
\hline & 2 & 12 & $\mathrm{~F}$ & 45 & 67 & 66 & 75 & 105 & 130 & - \\
\hline & 3 & 12 & $M$ & 67 & 50 & 47 & 170 & 210 & 250 & - \\
\hline & 4 & 13 & $M$ & 96 & 55 & 44 & 180 & 210 & 260 & - \\
\hline & 5 & 12 & $\mathrm{~F}$ & 59 & 49 & 50 & 60 & 70 & 85 & - \\
\hline & 6 & 12 & $M$ & 73 & 42 & 52 & 120 & 140 & 165 & - \\
\hline & 7 & 13 & $M$ & 73 & 46 & 34 & 110 & 130 & 145 & - \\
\hline \multirow[t]{13}{*}{ M } & 8 & 12 & $M$ & 81 & 38 & 35 & 130 & 145 & 170 & - \\
\hline & 9 & 13 & $\mathrm{~F}$ & 55 & 39 & 48 & 55 & 66 & 80 & - \\
\hline & 10 & 12 & $F$ & 49 & 45 & 35 & 50 & 70 & 80 & - \\
\hline & 11 & 12 & $\mathrm{~F}$ & 64 & 47 & 34 & 70 & 90 & 105 & - \\
\hline & 12 & 13 & $M$ & 73 & 46 & 41 & 80 & 105 & - & STOPED \\
\hline & 13 & 13 & $M$ & 81 & 42 & 48 & 90 & 110 & - & STOPED \\
\hline & 14 & 12 & $M$ & 96 & 48 & 42 & 90 & 120 & - & STOPED \\
\hline & 15 & 12 & $M$ & 96 & 30 & 22 & 70 & 80 & - & STOPED \\
\hline & 16 & 13 & $\mathrm{~F}$ & 64 & 25 & 25 & 50 & 55 & - & STOPED \\
\hline & 17 & 13 & $\mathrm{~F}$ & 55 & 31 & 27 & 60 & 66 & - & STOPED \\
\hline & 18 & 12 & $M$ & 67 & 28 & 20 & 70 & 80 & - & STOPED \\
\hline & 19 & 12 & $M$ & 89 & 29 & 32 & 75 & 80 & - & STOPED \\
\hline & 20 & 13 & $M$ & 61 & 31 & 20 & 65 & 70 & - & STOPED \\
\hline \multirow[t]{10}{*}{ W } & 21 & 13 & $M$ & 73 & 28 & 33 & 75 & 85 & - & STOPED \\
\hline & 22 & 12 & $\mathrm{~F}$ & 71 & 24 & 20 & 65 & 74 & - & STOPED \\
\hline & 23 & 12 & $\mathrm{~F}$ & 55 & 20 & 25 & 60 & 70 & - & STOPED \\
\hline & 24 & 13 & M & 102 & 29 & 19 & 100 & 110 & - & STOPED \\
\hline & 25 & 13 & $M$ & $102+$ & 32 & 22 & 105 & 120 & - & STOPED \\
\hline & 26 & 12 & $M$ & 67 & 19 & 26 & 80 & 100 & - & STOPED \\
\hline & 27 & 13 & $\mathrm{~F}$ & 64 & 28 & 21 & 70 & 78 & - & STOPED \\
\hline & 28 & 12 & $M$ & 81 & 25 & 20 & 90 & 100 & - & STOPED \\
\hline & 29 & 12 & $\mathrm{~F}$ & 45 & 23 & 32 & 50 & 55 & - & STOPED \\
\hline & 30 & 13 & $M$ & 73 & 31 & 27 & 80 & 95 & - & STOPED \\
\hline
\end{tabular}

$\mathrm{H}=($ Interest, Excitement) $>66.67, \mathrm{M}=33.34<$ (Interest, Excitement) $<66.7, \mathrm{~W}=($ Interest, Excitement $)<33.34$

Table (1) presents a description of the research sample in number, age, type, weight category (which the player competes), as well as averages of interest and excitement indicators during the first training program that lasted for 3 months. Moreover, it displays the record numbers of the total (snatch + clean and jerk) distributed on three measurements.

Table (2) shows the percentages of improvement in total numbers (Snatch + Clean and Jerk) between successive measurements displaying the differences between the three levels of players.

Table (2) Percentage of improvement in total between the two measures

\begin{tabular}{|c|c|c|c|c|c|c|}
\hline N & & $\begin{array}{c}\text { First Total } \\
\text { After } 3 \text { months } \\
\text { Training Pr. }\end{array}$ & $\begin{array}{l}\text { Second Total } \\
\text { Republic } \mathrm{CH} \text {. } \\
\text { 10/2018 }\end{array}$ & $\begin{array}{c}\text { Improvement Rate } \\
\%\end{array}$ & $\begin{array}{c}\text { Third Total } \\
\text { 12/2019 } \\
\text { Olympic } \\
\text { Center.maadi }\end{array}$ & $\begin{array}{c}\text { Improvement Rate } \\
\%\end{array}$ \\
\hline \multirow{4}{*}{$\mathrm{H}$} & 1 & 70 & 110 & 57.14 & 140 & 27.27 \\
\hline & 2 & 75 & 105 & 40.00 & 130 & 23.81 \\
\hline & 3 & 170 & 210 & 23.53 & 250 & 19.05 \\
\hline & 4 & 180 & 210 & 16.67 & 255 & 21.43 \\
\hline
\end{tabular}




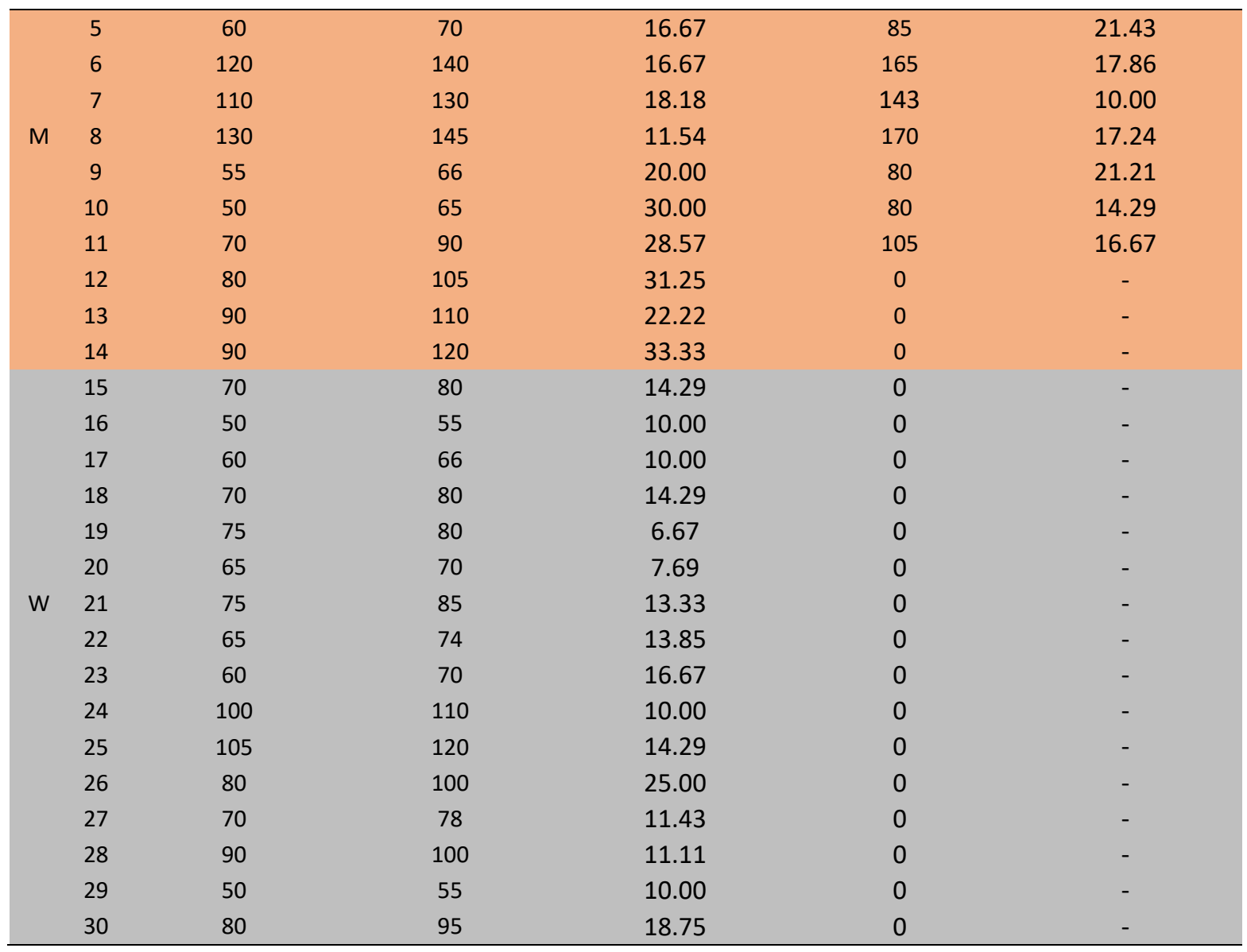

Table (2) depicts the improvement rates for the three targeted levels, where the rate of improvement for the (higher level) ranged between $40 \%$ to $60.00 \%$ in the first year and $23.81 \%$ to $27-27 \%$ in the second year. Likewise, the table displays the rate of improvement for the second group (medium level), which ranged between $11.54 \%$ and $33.33 \%$ in the first year, and ranged between $10 \%$ and $21.43 \%$. As for the third group (weak level), the rate of improvement in the first year ranged between $6.67 \%$ and $18.75 \%$, and in the second year, all its members retired from weightlifting.

\section{Discussion}

Figure (2) shows a diverse sample of interest and excitement measurements among players representing the three target groups of the measurement including the highest group measuring (higher than 66.67), the medium group between (33.34 and 66.67), and the weak group (less than 33.34). Also, Figure (3) shows various patterns of the shape of the nerve signals resulting from the brain while measuring indicators of interest and excitement for the three groups. And Table (3) shows the results of the players and the rates of the devolpment of their numbers, which would emphasize the importance of taking into account the psychological aspects when selecting players

Figure (2), Picture (1) shows a model for one of the weak group measurements, as the excitement indecator has a value of 11 and an interest indecator 29, and this all confirms that the player does not feel any kind of excitement towards the exercise or being attracted to it. And Figure (3) Picture (1) confirms this, as the form of nerve signals resulting from the brain of the same player in the same minute is limited and not sufficiently stimulated, which indicates that the mind is not attracted to this type of exercise.

This is in line with the results of a table (1), which suggest that the brain does not interact with different exercises, as the rate of players continuing to exercise weightlifting at that level (weak $<33.34$ ) for the second year 
was $0 \%$, meaning that the whole group left Weightlifting activity. which confirms the existence of a positive relationship between indicators of excitement, interest, and continuity in training.

This is confirmed by the results of Table (3), where the average improvements for the weak group in the first year ranged between $6.67 \%$ to $18.75 \%$, but with the second year the players began to retire one by one, as evidence that whenever the interest and excitement indicators decreased towards training activities, this predicts The level will low in the future, and thus retirement, as the practicing sport is not compatible with the player's tendencies

Figure (2), Picture (2) is a sample of the medium group, and it shows changes in the indicators of excitement and interest, as the result of the interest index increased to 50 and excitement to 62 , which makes this model more psychologically attracted to the exercises practiced during training, and therefore a greater opportunity for continuity. Figure (3), Picture (2) shows that, as the shape of the nerve signals generated by the brain of the same player in the same minute is more active than picture (1)( weak group), which indicates that the mind is physically attracted to this type of exercise.

This is confirmed by the results of Table (2), which shows the rate of development in the total records for the players, as the rate of development after the first training year ranged between $11.54 \%$ and $33.33 \%$ and after the second year of training ranged between $10.00 \%$ and $21.43 \%$. as at this level retired from training only 3 players out of 12 players, or $25 \%$ after two years of training, This is evidence of continuity whenever there is a more psychological connection with the type of activity, the chances of continuity and development in it are more.

Figure (2), Picture (3) is one of the best models in terms of indicators of excitement and interest. In the picture, the interest index reached 74 and the excitement index 72 , which means that the player is in complete harmony and interacting with exercises performed in sports activity, and looking at figure (3) picture (3) we find a picture of nerve signals resulting from The brain suggests the interaction of all centers of the sense of the brain, which demonstrates the complete integration and preoccupation of the mind with the activity practiced.

Table (2) confirms this, as the rate of development of the digital level of the two players in the first year was $40 \%$ and $57.14 \%$, and the development of their numbers in the second year was $23.81 \%$ and $27.27 \%$. Looking at Table (1), we find that one of the two players participated in the Afro-Asian championship and scored second place.

All These results are in agreement with many studies that emphasized the necessity of psychological testing for applicants and taking into account compatible tendencies not only in the field of sports, but also in various jobs such as the police or teaching. Whether physical or mental, this requires special psychological capabilitiesbased on the previously mentioned example. A study by Robert E. Cochrane, Robert P. Tett, Leon Vandecreek 2003 (Psychological Testing and the Selection of Police Officers: A National Survey) that stressed the importance of observing psychological tests when selecting Amircan police officers, and a study by Hamid, S. F., Nordin, N., Adnan, A. A., \& Sirun, N. (2013) (A study on primary school teachers' organizational commitment and psychological empowerment in the district of klang) that emphasized the need to pay attention to the results of psychological tests when choosing teachers

\section{Conclusion}

When selecting the young weightlifters, the focus should be on the different psychological aspects represented in the interest and excitement during the performance and the follow-up of the players and the extent of the consistency of this activity with their psychological inclinations, as it is not necessarily successful in the activity just because of physical capabilities. This is proven by the digital results of the medium group in the research.Continuing to train and achieve higher levels is more related to their interest and excitement towards the activity being practiced.

\section{References}


Akyüz, M., Agar, M., Akyüz, Ö., \& Dogru, Y. (2016). Motivational Factors Affecting Athletes in Selecting the Sport Branches of Athletics, Ski and Tennis. Journal of Education and Training Studies, 4(12), 160-165.

Awad, A. (2017). Outcome strength of weightlifters, bilateral limb deficit, relative strength and its relationship to Women Arab Championships results (senior) 2017. Turkish Journal of Kinesiology, 4(1), 26-32.

Awed, A. (2019). Effectiveness of CrossFit drills on muscular endurance and Consecutive attempts cases for youth weightlifters. International Journal of Sports Science and Arts, 3(03), 19-43.

Cochrane, R. E., Tett, R. P., \& Vandecreek, L. (2003). Psychological testing and the selection of police officers: A national survey. Criminal Justice and Behavior, 30(5), 511-537.

Daus, A. T., Wilson, J., \& Freeman, W. M. (1986). Psychological testing as an auxiliary means of selecting successful college and professional football players. Journal of sports medicine and physical fitness, 26(3), $274-278$.

Ebada, K. (2011). Relative strength, Body mass and height as Predictors of Olympic Weightlifting Players Performance. Selçuk Unıversıty Journal of Physıcal Educatıon and Sport Scıence, 13(2), 166-171.

EMOTIV: EMOTIV Insight Advanced Brainwear ${ }^{\circledR}$ for Brain Computer Interface [online]. [Cit. 2019-12-31]. Available on: https://www.emotiv.com/myemotiv/

Grossmann, T., \& Johnson, M. H. (2010). Selective prefrontal cortex responses to joint attention in early infancy. Biology letters, 6(4), 540-543.

Hassan, A. (2014). Establishing Physical Skill Test Battery for Selecting Hight Levels Weightlifters. Damietta University Publication, 1(7).

Hamid, S. F., Nordin, N., Adnan, A. A., \& Sirun, N. (2013). A study on primary school teachers' organizational commitment and psychological empowerment in the district of klang. Procedia-Social and Behavioral Sciences, 90, 782-787.

Khaled, E. (2013). Anthropometric measurements, somatotypes and physical abilities as a function to predict the selection of talents junior weightlifters. Journal of Science, Movement and Health, 8(2), 166-172.

Kurade, N. P. (2014). An intelligent method for selecting and recommending best players to help build sports team. International Journal of Computer Applications, 105(7).

Porat, Y., Lufi, D., \& Tenenbaum, G. (1989). Psychological components contribute to select young female gymnasts. International Journal of Sport Psychology, 20(4), 279-286.

Strmiska, M., Koudelková, Z., \& Žabčíková, M. (2018). Measuring brain signals using emotiv devices. WSEAS Transactions on Systems and Control. 
(Attachment 1)

Standard Selection Form 


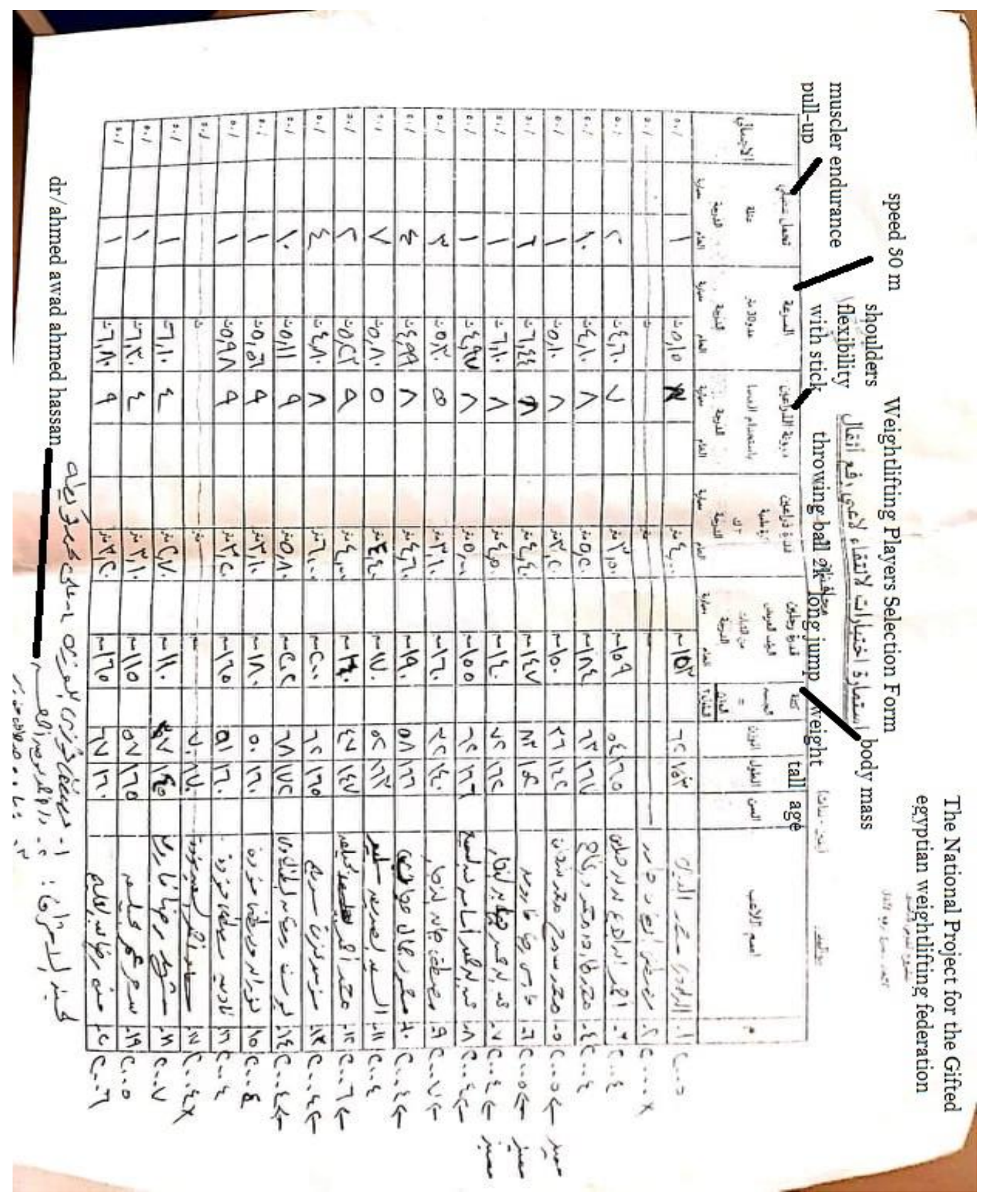

(Attachment 2)

Attendance ratios for players in training 


\begin{tabular}{|c|c|c|c|c|c|c|c|}
\hline & N & $\begin{array}{c}\text { Units } \\
\text { number } \\
36\end{array}$ & $\begin{array}{l}\text { Attendance ratios } \\
\text { for } 3 \text { months } \\
\text { Training Pr. \% }\end{array}$ & $\begin{array}{c}\text { Units } \\
\text { number } \\
112\end{array}$ & $\begin{array}{l}\text { Attendance } \\
\text { ratios to Republic } \\
\text { CH. 10/2018\% }\end{array}$ & $\begin{array}{c}\text { Units } \\
\text { number } \\
177\end{array}$ & $\begin{array}{c}\text { Attendance ratios } \\
\text { to } 12 / 2019 \\
\text { Olympic } \\
\text { Center.maadi } \%\end{array}$ \\
\hline \multirow{7}{*}{$\mathrm{H}$} & 1 & 36 & 100.00 & 105 & 93.75 & 170 & 96.05 \\
\hline & 2 & 36 & 100.00 & 105 & 93.75 & 170 & 96.05 \\
\hline & 3 & 34 & 94.44 & 100 & 89.29 & 165 & 93.22 \\
\hline & 4 & 34 & 94.44 & 95 & 84.82 & 162 & 91.53 \\
\hline & 5 & 35 & 97.22 & 92 & 82.14 & 140 & 79.10 \\
\hline & 6 & 33 & 91.67 & 90 & 80.36 & 135 & 76.27 \\
\hline & 7 & 32 & 88.89 & 85 & 75.89 & 120 & 67.80 \\
\hline \multirow[t]{13}{*}{ M } & 8 & 36 & 100.00 & 96 & 85.71 & 129 & 72.88 \\
\hline & 9 & 36 & 100.00 & 85 & 75.89 & 114 & 64.41 \\
\hline & 10 & 35 & 97.22 & 90 & 80.36 & 110 & 62.15 \\
\hline & 11 & 32 & 88.89 & 100 & 89.29 & 122 & 68.93 \\
\hline & 12 & 33 & 91.67 & 88 & 78.57 & 45 & 25.42 \\
\hline & 13 & 32 & 88.89 & 79 & 70.54 & 52 & 29.38 \\
\hline & 14 & 33 & 91.67 & 81 & 72.32 & 50 & 28.25 \\
\hline & 15 & 30 & 83.33 & 70 & 62.50 & 20 & 11.30 \\
\hline & 16 & 32 & 88.89 & 65 & 58.04 & 30 & 16.95 \\
\hline & 17 & 27 & 75.00 & 66 & 58.93 & 29 & 16.38 \\
\hline & 18 & 30 & 83.33 & 70 & 62.50 & 32 & 18.08 \\
\hline & 19 & 29 & 80.56 & 62 & 55.36 & 19 & 10.73 \\
\hline & 20 & 33 & 91.67 & 52 & 46.43 & 25 & 14.12 \\
\hline \multirow[t]{10}{*}{ w } & 21 & 31 & 86.11 & 55 & 49.11 & 22 & 12.43 \\
\hline & 22 & 32 & 88.89 & 49 & 43.75 & 14 & 7.91 \\
\hline & 23 & 31 & 86.11 & 60 & 53.57 & 13 & 7.34 \\
\hline & 24 & 30 & 83.33 & 51 & 45.54 & 16 & 9.04 \\
\hline & 25 & 30 & 83.33 & 58 & 51.79 & 20 & 11.30 \\
\hline & 26 & 35 & 97.22 & 54 & 48.21 & 25 & 14.12 \\
\hline & 27 & 35 & 97.22 & 50 & 44.64 & 16 & 9.04 \\
\hline & 28 & 35 & 97.22 & 46 & 41.07 & 10 & 5.65 \\
\hline & 29 & 29 & 80.56 & 40 & 35.71 & 12 & 6.78 \\
\hline & 30 & 33 & 91.67 & 44 & 39.29 & 17 & 9.60 \\
\hline
\end{tabular}

